\title{
Susceptibility of Ternary Aluminum Alloys to Cracking during Solidification
}

\author{
Jiangwei Liu ${ }^{\mathrm{a}}$ and Sindo Kou ${ }^{\mathrm{b}, *}$
}

${ }^{\mathrm{a}}$ School of Energy Science and Engineering, Central South University, Changsha, 410083, China

${ }^{\mathrm{b}}$ Department of Materials Science and Engineering, University of Wisconsin, Madison, WI 53706 USA

Abstract The crack susceptibility map of a ternary Al alloy system provides useful information about which alloy compositions are most susceptible to cracking and thus should be avoided by using a filler metal with a significantly different composition. In the present study the crack susceptibility maps of ternary Al alloy systems were calculated based on the maximum $\left|d T / d\left(f_{S}\right)^{1 / 2}\right|$ as an index for the crack susceptibility, where $T$ is temperature and $f_{S}$ fraction solid. Due to the complexity associated with ternary alloy solidification, commercial thermodynamic software Pandat and Al database PanAluminum, instead of analytical equations, were used to calculate $f_{S}$ as a function of $T$ and hence the maximum $\left|d T / d\left(f_{S}\right)^{1 / 2}\right|$ for ternary Al-Mg-Si, Al$\mathrm{Cu}-\mathrm{Mg}$ and $\mathrm{Al}-\mathrm{Cu}-\mathrm{Si}$ alloy systems. A crack susceptibility map covering 121 alloy compositions was constructed for each of the three ternary alloy systems at each of the following three levels of back diffusion: no back diffusion, back diffusion under a $100{ }^{\circ} \mathrm{C} / \mathrm{s}$ cooling rate, and back diffusion under $20^{\circ} \mathrm{C} / \mathrm{s}$. The location of the region of high crack susceptibility, which is the most important part of the map, was shown in each of the nine calculated maps. These locations were compared with those observed in crack susceptibility tests by previous investigators. With back diffusion considered, either under 20 or $100{ }^{\circ} \mathrm{C} / \mathrm{s}$, the agreement between the calculated and observed maps was good especially for $\mathrm{Al}-\mathrm{Mg}-\mathrm{Si}$ and $\mathrm{Al}-\mathrm{Cu}-\mathrm{Mg}$. Thus, the maximum $\left|d T / d\left(f_{S}\right)^{1 / 2}\right|$ can be used as a crack susceptibility index to construct crack susceptibility maps for ternary $\mathrm{Al}$ alloys and to evaluate the effect of back diffusion on their crack susceptibility.

*Corresponding author. 


\section{Introduction}

Cracking during solidification of an alloy is a serious defect, called solidification cracking in welding [1] and hot tearing in casting [2, 3]. During welding of an alloy, a semisolid region, called the mushy zone, exists between the weld pool and the completely solidified weld metal. In the mushy zone the solid phase usually exists in the form of columnar dendritic grains, separated by the liquid phase along grain boundaries. The fraction solid $f_{S}$ continues to increase as temperature $T$ decreases toward the end of the mushy zone. Cracking usually occurs during the terminal stage of solidification (near $f_{S}=1$ ) along grain boundaries, where a small amount of liquid can still exist to form thin liquid films between grains to keep them from bonding together to resist cracking. The prominent RDG model of Rappaz, Drezet and Gremaud [4] was the first hot tearing model with a physically sound basis. However, the grain boundary, where cracking occurs, was not yet taken into account.

Kou [5] considered three factors at the grain boundary. Suppose two columnar dendritic grains are growing side by side in their axial direction in the mushy zone. The first factor is the lateral separation of grains from each other under tensile strain to cause cracking. The second factor is the lateral growth of grains toward each other to bond together (called bridging) to resist cracking. The third factor is the liquid feeding along the grain boundary to resist cracking. Tension is induced because the mushy zone cannot contract freely under solidification shrinkage and thermal contraction especially when the workpiece is rigid or clamped down tightly. Kou [5] showed during terminal solidification the lateral growth rate of a columnar dendritic grain is proportional to $\left|d\left(f_{S}\right)^{1 / 2} / d T\right|$. Based on the consideration of the space in a volume element positioned between the two grains near $\left(f_{S}\right)^{1 / 2}=1$, an equation was derived to serve as the criterion for cracking to occur during solidification. According to the criterion, if the rate of 
space increase due to grain separation minus the rate of space decrease due to lateral grain growth exceeds the rate of space decrease due to liquid feeding, a void can form in the volume element, that is, a crack can form at the grain boundary.

Kou [5] further showed that in a plot of $T$ vs. $\left(f_{S}\right)^{1 / 2}$, the steepness $\left|d T / d\left(f_{S}\right)^{1 / 2}\right|$ near $\left(f_{S}\right)^{1 / 2}$ $=1$ can be considered as an index for the crack susceptibility. Since the slope $d T / d\left(f_{S}\right)^{1 / 2}$ is negative, it is more convenient to deal with its absolute value, that is, the steepness $\left|d T / d\left(f_{S}\right)^{1 / 2}\right|$. The reasons $\left|d T / d\left(f_{S}\right)^{1 / 2}\right|$ near $\left(f_{S}\right)^{1 / 2}=1$ can be used as the crack susceptibility index are as follows. First, the higher $\left|d T / d\left(f_{S}\right)^{1 / 2}\right|$ is, the slower the lateral growth rate becomes, that is, the slower the two neighboring columnar grains grow toward each other to bond together and resist cracking. Second, with slow lateral growth the columnar grains can grow very long without bridging. This means the intergranular liquid channel can be very long and hence difficult for liquid to flow through it (due to viscosity of liquid [8]) to feed shrinkage and resist cracking. Third, a long intergranular liquid channel can act as a long sharp notch to promote crack initiation. Thus, $\left|d T / d\left(f_{S}\right)^{1 / 2}\right|$ near $\left(f_{S}\right)^{1 / 2}=1$ can be used as an index for the susceptibility to cracking during solidification. To calculate the index, a short interval of $\left(f_{S}\right)^{1 / 2}$ near $\left(f_{S}\right)^{1 / 2}=1$ can be taken as $\Delta\left(f_{S}\right)^{1 / 2}$ and the corresponding temperature interval can be taken as $\Delta T$ to calculate the $\left|\Delta T / \Delta\left(f_{S}\right)^{1 / 2}\right|$ near $\left(f_{S}\right)^{1 / 2}=1[5]$. An alternative is to use the maximum steepness $\left|d T / d\left(f_{S}\right)^{1 / 2}\right|$ if it occurs near $\left(f_{S}\right)^{1 / 2}=1$. The curves of $T$ vs. $\left(f_{S}\right)^{1 / 2}$ for binary $\mathrm{Al}$ alloys and commercial wrought $\mathrm{Al}$ alloys showed that the maximum steepness $\left|d T / d\left(f_{S}\right)^{1 / 2}\right|$ occurs near $\left(f_{S}\right)^{1 / 2}=1$ [5]. Thus, Kou [9] also proposed to use the maximum $\left|d T / d\left(f_{S}\right)^{1 / 2}\right|$ as the crack susceptibility index.

The $T-\left(f_{S}\right)^{1 / 2}$ curve shows $\left(f_{S}\right)^{1 / 2}$ continues to increase as $T$ decreases during solidification. Thus, near the end of solidification, there exists a point where liquid still remains but is no longer enough in quantity to form continuous liquid films to separate the grains. At this point, extensive 
bonding between grains, i.e., extensive bridging, can occur to end the crack susceptibility. Let $f_{S B}$ be the fraction solid at which extensive bridging occurs to end the crack susceptibility. Kou [9] assumed that $\left(f_{S B}\right)^{1 / 2}=0.99$, that is, $f_{S B}=0.98$. It has been shown that $\left(f_{S B}\right)^{1 / 2}=0.99$ works well for $\mathrm{Al}$ alloys [9]. Since the crack susceptibility ends at $f_{S B}$, if $\left|d T / d\left(f_{S}\right)^{1 / 2}\right|$ continues to increase beyond $\left(f_{S}\right)^{1 / 2}=0.99$, the maximum $\left|d T / d\left(f_{S}\right)^{1 / 2}\right|$ before or at $\left(f_{S}\right)^{1 / 2}=0.99$ should be used. The RDG model also assumed $f_{S B}=0.98[4]$.

Kou [9] verified the validity of using the maximum $\left|d T / d\left(f_{S}\right)^{1 / 2}\right|$ as the crack susceptibility index. He showed that a filler metal that is known to reduce the crack susceptibility of an alloy (e.g., filler metal $4145 \mathrm{Al}$ for welding $2014 \mathrm{Al}$ and filler metal $4043 \mathrm{Al}$ for welding $6061 \mathrm{Al}$ and $7075 \mathrm{Al})$ reduces the maximum $\left|d T / d\left(f_{S}\right)^{1 / 2}\right|$ of the alloy. He also showed that the maximum $\left|d T / d\left(f_{S}\right)^{1 / 2}\right|$ increases in the order of 2219, 2014, 2024, 6061 and $7075 \mathrm{Al}$, consistent with their ranking in crack susceptibility tests of welds. In addition, he showed that $\mathrm{Al}$ casting alloy A206 is more susceptible to hot tearing than A356 [5]. Thermodynamic software Pandat [10] and Al database PanAluminum [11] were used to calculate the maximum $\left|d T / d\left(f_{S}\right)^{1 / 2}\right|$, assuming negligible back diffusion of the solute from the interdendritic liquid to the Al-rich dendrites, that is, the Scheil solidification model, which is also called the Gulliver-Scheil solidification model [12, 13].

Binary $\mathrm{Al}-\mathrm{Si}, \mathrm{Al}-\mathrm{Cu}$ or $\mathrm{Al}-\mathrm{Mg}$ alloy systems were also analyzed based on the maximum $\left|d T / d\left(f_{S}\right)^{1 / 2}\right|$ as the crack susceptibility index [9]. When the maximum $\left|d T / d\left(f_{S}\right)^{1 / 2}\right|$ is plotted against the solute content, a $\lambda$-shaped crack-susceptibility curve with a peak was obtained, consistent with the $\lambda$-shaped curves observed in crack-susceptibility tests of binary Al alloys. The location of the peak is the most important information provided by the crack susceptibility curve because it indicates the solute content most susceptible to cracking. A filler metal with a 
very different solute content can thus be used to change the weld metal composition and move it away from the peak to reduce the crack susceptibility. The height of the peak, on the other hand, shows the level of the highest crack susceptibility.

Subsequently, Liu and Kou [14] considered back diffusion during solidification by using the following equation of Kurtz and Fisher [15] to calculate $f_{S}$ as a function of temperature $T$ :

$$
f_{S}=\frac{1}{1-2 \alpha^{\prime} k}\left[1-\left(\frac{T_{m}-T}{T_{m}-T_{L}}\right)^{\frac{1-2 \alpha^{\prime} k}{k-1}}\right]
$$

where

$$
\begin{aligned}
& \alpha^{\prime}=\alpha\left[1-\exp \left(-\frac{1}{\alpha}\right)\right]-\frac{1}{2} \exp \left(-\frac{1}{2 \alpha}\right) \\
& \alpha=\frac{4 D_{S} t_{f}}{\lambda_{2}^{2}}
\end{aligned}
$$

$k$ is equilibrium segregation coefficient, $T_{m}$ melting point of pure $\mathrm{Al}, T_{L}$ liquidus temperature, $D_{S}$ diffusion coefficient of solute in solid dendrites, $t_{f}$ local freezing (solidification) time, and $\lambda_{2}$ secondary dendrite arm spacing. In Eq. (1) the solidus and liquidus lines are assumed straight lines, i.e., $k$ is constant. Without diffusion, $\alpha=\alpha^{\prime}=0$ and Eq. (2) reduces to the simple Scheil equation [12,13]. Liu and Kou [16] derived simple analytical equations to calculate the location and height of the peak in the crack susceptibility curve of binary alloys. To deal with binary phase diagrams with curved solidus and liquidus lines such as Al-Zn and Al-Sn, Liu and Kou [17] calculated $f_{S}$ as a function of $T$ by numerical integration.

Liu and Kou [18] quenched the mushy zone and measured the cooling curve during gastungsten arc welding of $\mathrm{Al}$ alloys. Microstructural examination and composition analysis by 
EPMA (electron probe microanalysis) showed that significant back diffusion occurred in both $2014 \mathrm{Al}(\sim \mathrm{Al}-4.4 \mathrm{Cu})$ and $5086 \mathrm{Al}(\sim \mathrm{Al}-4.0 \mathrm{Mg})$ during solidification.

2. Calculation of $T$ vs. $\left(f_{S}\right)^{1 / 2}$

Ternary alloy solidification is significantly more complicated than binary alloy solidification. Consequently, simple analytical equations can no longer be used, such as the Scheil equation (no diffusion) [12, 13] or the equation of Kurtz and Fisher (back diffusion) [15]. Instead, commercial thermodynamic software Pandat [10] and Al-alloy database PanAluminum [11] were used to calculate $T$ vs. $f_{S}$ for ternary $\mathrm{Al}$ alloys with and without back diffusion. The diffusion coefficients were already provided in PanAluminum based on the data in the handbook of Neumann and Tuijin [19]. In addition to the alloy composition, the cooling rate (through the freezing temperature range $\Delta T_{f}$ ) and the secondary dendrite arm spacing $\lambda_{2}$ also need to be specified when using Pandat to calculate $T$ vs. $f_{S}$ involving back diffusion. Liu and Kou [18] measured the cooling rate during gas-tungsten arc welding (GTAW) of 2014 Al. The workpiece was $102 \mathrm{~mm}$ by $102 \mathrm{~mm}$ by $2.0 \mathrm{~mm}$, and the welding conditions were direct current electrode negative (DCEN), 100 A welding current, $13 \mathrm{~V}$ welding voltage, $4.25 \mathrm{~mm} / \mathrm{s}$ torch travel speed, and high-purity Ar shielding (i.e., standard welding grade Ar). The cooling rate $\Delta T_{f} / \Delta t$ was essentially constant at $95^{\circ} \mathrm{C} / \mathrm{s}$. They also measured the cooling rate during GTAW of $5086 \mathrm{Al}$. The workpiece was $102 \mathrm{~mm}$ by $102 \mathrm{~mm}$ by $1.6 \mathrm{~mm}$, and the welding conditions were identical to those for $2014 \mathrm{Al}$ except the welding current was reduced to $80 \mathrm{~A}$ in view of the smaller workpiece thickness of $1.6 \mathrm{~mm}$. The cooling rate $\Delta T_{f} / \Delta t$ was essentially constant at $101{ }^{\circ} \mathrm{C} / \mathrm{s}$. Since the cooling rates were close to $100^{\circ} \mathrm{C} / \mathrm{s}$ in both cases, the cooling rate of $100^{\circ} \mathrm{C} / \mathrm{s}$ was used in the present study. 
Fig. 1 summarizes the data of $\lambda_{2} v s$. the cooling rate in both welding and casting [14]. So, if the cooling rate is taken as $100^{\circ} \mathrm{C} / \mathrm{s}$, the corresponding secondary dendrite arm spacing $\lambda_{2}$ is $10 \mu \mathrm{m}$ according to Fig. 1 . This $\lambda_{2}$ of $10 \mu \mathrm{m}$ is close to that of $8.8 \mu \mathrm{m}$ measured in the $2014 \mathrm{Al}$ weld (and in the $5086 \mathrm{Al}$ weld at locations where dendrites were visible) [18]. A much slower cooling rate of $20^{\circ} \mathrm{C} / \mathrm{s}$ was also used in the present study, which corresponds to $\lambda_{2}$ of $18 \mu \mathrm{m}$ as shown in Fig. 1. This $\lambda_{2}$ is inside the range of gas-metal arc welding or even casting.

Since the freezing temperature range was calculated automatically by Pandat [10], the local freezing time $t_{f}$ was also calculated automatically based on the cooling rates specified. Thus, based on the diffusion coefficient $\left(D_{S}\right)$ data (in Al database PanAluminum [11]), the local solidification time $t_{f}$ and the secondary dendrite arm spacing $\lambda_{2}, T v s . f_{S}$ was calculated numerically by Fick's second law [8] using the Pan Solidification module in Pandat [10].

$T$ vs. $f_{S}$ was calculated for the ternary $\mathrm{Al}-\mathrm{Mg}-\mathrm{Si}, \mathrm{Al}-\mathrm{Cu}-\mathrm{Mg}$ and $\mathrm{Al}-\mathrm{Cu}-\mathrm{Si}$ alloy systems. Take the ternary Al-Mg-Si alloy system as an example. The calculation of $T v s . f_{S}$ was carried out from 0 to $5 \mathrm{wt} \% \mathrm{Mg}$ at the interval of $0.5 \mathrm{wt} \% \mathrm{Mg}$ and from 0 to $5 \mathrm{wt} \% \mathrm{Si}$ at the interval of 0.5 wt $\%$ Si. This covered a total of $121(=11 \times 11)$ alloys in the ternary Al-Mg-Si alloy system. For each alloy a curve of $T$ vs. $\left(f_{S}\right)^{1 / 2}$ was plotted and the maximum steepness of the curve $\left|d T / d\left(f_{S}\right)^{1 / 2}\right|$ calculated. The calculated values of the maximum steepness $\left|d T / d\left(f_{S}\right)^{1 / 2}\right|$ of the 121 alloys were used to construct a crack susceptibility map for the ternary Al-Mg-Si alloy system using the commercial plotting software Tecplot [20].

The above procedure was repeated for each of the following three different conditions: without back diffusion, with back diffusion under a $100{ }^{\circ} \mathrm{C} / \mathrm{s}$ cooling rate and with back diffusion under a $20{ }^{\circ} \mathrm{C} / \mathrm{s}$ cooling rate. Thus, three crack susceptibility maps were calculated for the ternary 
Al-Mg-Si alloy system. These maps allowed the effect of back diffusion on the crack susceptibility of the ternary Al-Mg-Si alloy system to be examined.

All the above procedure for the ternary Al-Mg-Si alloy system was repeated for the ternary alloy systems $\mathrm{Al}-\mathrm{Cu}-\mathrm{Mg}$ and $\mathrm{Al}-\mathrm{Cu}-\mathrm{Si}$. Since the crack susceptibility of pure Al is zero and does not need to be calculated, a total of $1080(=(121-1) \times 3 \times 3)$ sets calculations of $T v s$. $\left(f_{S}\right)^{1 / 2}$ and the maximum steepness $\left|d T / d\left(f_{S}\right)^{1 / 2}\right|$ were conducted.

\section{Results and Discussion}

\subsection{Al-Mg-Si}

The calculated results for the ternary Al-Mg-Si alloy system are shown in Figs. 2 through 4. As mentioned previously, the curves of $T v s .\left(f_{S}\right)^{1 / 2}$ were calculated first for the 121 alloy in the systems, examples of which are shown in Fig. 3. For each alloy, the maximum steepness $\left|d T / d\left(f_{S}\right)^{1 / 2}\right|$ of its $T-\left(f_{S}\right)^{1 / 2}$ curve was then plotted against its composition, either as a cracksusceptibility curve along a line of constant Mg content (Fig. 4) or as a crack susceptibility map (Fig. 2). For convenience, the crack susceptibility map will be discussed first.

Fig. 2 shows the crack susceptibility maps of the ternary Al-Si-Mg alloy system. Without back diffusion, as shown in Fig. 2a, the highest crack susceptibility is $1.4 \times 10^{4} \mathrm{C}$ and is located near Al-2.5Mg. The crack susceptibility is expressed in ${ }^{\circ} \mathrm{C}$ because the crack susceptibility index is the maximum steepness $\left|d T / d\left(f_{S}\right)^{1 / 2}\right|$, which has the unit of ${ }^{\circ} \mathrm{C}$. With back diffusion under a $100^{\circ} \mathrm{C} / \mathrm{s}$ cooling rate, as shown in Fig. $2 \mathrm{~b}$, the highest crack susceptibility drops to $3.2 \times 10^{3}{ }^{\circ} \mathrm{C}$ and its location shifts to near Al-0.5Mg-0.5Si. Allowing significantly more time for back diffusion to occur under a slower cooling rate of $20^{\circ} \mathrm{C} / \mathrm{s}$, as shown in Fig. 2c, the highest crack susceptibility drops only slightly to $2.6 \times 10^{3}{ }^{\circ} \mathrm{C}$ and its location shifts slightly to near Al$0.75 \mathrm{Mg}-0.75 \mathrm{Si}$. Thus, for the ternary $\mathrm{Al}-\mathrm{Si}-\mathrm{Mg}$ alloy system, back diffusion can reduce the 
highest crack susceptibility significantly. More importantly, it can also shift the location of the highest crack susceptibility significantly.

Fig. 2d shows the crack susceptibility map constructed based on the results of crack susceptibility tests of the ternary Al-Mg-Si alloy system using the ring-casting method [21], which is a method for testing cracking during solidification in casting and welding $[1,3]$. In this method the total length of cracks is used as the index for the crack susceptibility. The region in the map with crack lengths longer than 7 inches $(17.78 \mathrm{~cm})$ is marked in red color as the region of high crack susceptibility. This is the most important information provided by the crack susceptibility map. By selecting a filler metal with a composition far away from this region, the weld metal composition can be shifted away from this region to reduce the crack susceptibility significantly. As can be seen by comparing Fig. 2d with Fig. 2c, the observed and calculated regions of high crack susceptibility are very close to each other. The widely used Al alloy 6061 ( Al-1.0Mg-0.6Si) is known to have a high susceptibility to solidification cracking when welded without a filler metal. The high crack susceptibility of $6061 \mathrm{Al}$ can be seen in both Fig. $2 \mathrm{c}$ and $2 \mathrm{~d}$. This confirms the validity of both the calculated map (Fig. 2c) and the experimentally constructed map (Fig. 2d). To reduce the crack susceptibility effectively, filler metal $4043 \mathrm{Al}$ ( $\mathrm{Al}-5 \mathrm{Si})$ or $5356 \mathrm{Al}(\sim \mathrm{Al}-5 \mathrm{Mg})$ has been used in practice to move the weld metal composition away from that of $6061 \mathrm{Al}$ [1]. The good agreement between Fig. 2c and 2d indicates that the maximum $\left|d T / d\left(f_{S}\right)^{1 / 2}\right|$ can be used for the ternary Al-Mg-Si alloy system as the index for the crack susceptibility and that back diffusion can affect its crack susceptibility significantly.

In the crack susceptibility map in Fig. $2 \mathrm{c}$ for the cooling rate of $20^{\circ} \mathrm{C} / \mathrm{s}$, a horizontal line at $0.5 \mathrm{wt} \% \mathrm{Mg}$ can be drawn across the map through the region of high crack susceptibility. The curves of $T$ vs. $\left(f_{S}\right)^{1 / 2}$ for alloys along this line are shown in Fig. 3. For comparison, a horizontal 
line at $0.5 \mathrm{wt} \% \mathrm{Mg}$ is also drawn across the map for no back diffusion in Fig. 2a, and their curves of $T$ vs. $\left(f_{S}\right)^{1 / 2}$ are included in Fig. 3. As mentioned previously, extensive bridging is assumed to occur at $\left(f_{S}\right)^{1 / 2}=0.99$ to end the crack susceptibility, as shown by the vertical dotted line at $\left(f_{S}\right)^{1 / 2}=0.99$. The maximum steepness $\left|d T / d\left(f_{S}\right)^{1 / 2}\right|$ of an alloy is indicated by a tangent line to the $T-\left(f_{S}\right)^{1 / 2}$ curve of the alloy. For instance, in Fig. 3a for no back diffusion the tangents to the $T-\left(f_{S}\right)^{1 / 2}$ curves of the four alloys with $0,0.5,1$ and $1.5 \mathrm{wt} \% \mathrm{Si}$ are shown. As can be seen, the alloy with $0.5 \mathrm{wt} \% \mathrm{Si}$, that is, alloy $\mathrm{Al}-0.5 \mathrm{Mg}-0.5 \mathrm{Si}$, shows the highest maximum steepness $\left|d T / d\left(f_{S}\right)^{1 / 2}\right|$. The case of back diffusion under a $20{ }^{\circ} \mathrm{C} / \mathrm{s}$ cooling rate is shown in Fig. 3b. The alloy with $1.0 \mathrm{wt} \% \mathrm{Si}$, that is, alloy $\mathrm{Al}-0.5 \mathrm{Mg}-1 \mathrm{Si}$, shows the highest maximum steepness $\left|d T / d\left(f_{S}\right)^{1 / 2}\right|$.

For each alloy in Fig. 3, the maximum steepness $\left|d T / d\left(f_{S}\right)^{1 / 2}\right|$ of the alloy is plotted against the composition of the alloy as shown in Fig. 4 for the cases of no back diffusion and back diffusion under $20{ }^{\circ} \mathrm{C} / \mathrm{s}$. For comparison, the case of back diffusion under $100{ }^{\circ} \mathrm{C} / \mathrm{s}$ is also included in Fig. 4. The curve for the case of no back diffusion shows a peak at $0.5 \mathrm{wt} \% \mathrm{Si}$, that is, alloy $\mathrm{Al}-0.5 \mathrm{Mg}-0.5 \mathrm{Si}$ is the most crack susceptible alloy among the ternary $\mathrm{Al}-\mathrm{Mg}$ - $\mathrm{Si}$ alloys with a constant $\mathrm{Mg}$ content of $0.5 \mathrm{wt} \%$. Likewise, the curve for back diffusion under $20{ }^{\circ} \mathrm{C} / \mathrm{s}$ shows a peak at about $1 \mathrm{wt} \% \mathrm{Si}$, indicating alloy $\mathrm{Al}-0.5 \mathrm{Mg}-1 \mathrm{Si}$ is the most crack susceptible alloy among the ternary Al-Mg-Si alloys with a constant Mg content of $0.5 \mathrm{wt} \%$.

\subsection{Al-Cu-Mg}

Fig. 5 shows the crack susceptibility maps of the ternary Al-Cu-Mg system. Again, the crack susceptibility decreases in the order of no back diffusion, back diffusion under the cooling rate of $100^{\circ} \mathrm{C} / \mathrm{s}$ and back diffusion under the cooling rate of $20^{\circ} \mathrm{C} / \mathrm{s}$. Without back diffusion the highest crack susceptibility is $1.4 \times 10^{4}{ }^{\circ} \mathrm{C}$ and near Al-2.5Mg as shown in Fig.5a. With back 
diffusion under the cooling rate of $100^{\circ} \mathrm{C} / \mathrm{s}$, the highest crack susceptibility, as shown in Fig. $5 \mathrm{~b}$, is $6.5 \times 10^{3}{ }^{\circ} \mathrm{C}$ and near $\mathrm{Al}-1.8 \mathrm{Cu}-1.1 \mathrm{Mg}$. With back diffusion under the cooling rate of $20^{\circ} \mathrm{C} / \mathrm{s}$, the highest crack susceptibility is $6.0 \times 10^{3} \mathrm{C}$ and near Al-2Cu-1.3Mg as shown in Fig. 5c.

Fig. 5d shows the ternary Al-Cu-Mg crack susceptibility map constructed based on the results of crack susceptibility tests using the ring-casting method [22]. As shown, the highest crack susceptibility is near $\mathrm{Al}-2 \mathrm{Cu}-1.5 \mathrm{Mg}$ as shown in Fig. 5d. Thus, the calculated highest crack susceptibility near $\mathrm{Al}-2 \mathrm{Cu}-1.3 \mathrm{Mg}$ in Fig. $5 \mathrm{c}$ is close to the observed one in Fig. 5d. This good agreement indicates that, for the ternary $\mathrm{Al}-\mathrm{Cu}-\mathrm{Mg}$ alloy system, the maximum $\left|d T / d\left(f_{S}\right)^{1 / 2}\right|$ can be used as the index to calculate the region of high crack susceptibility and that back diffusion can affect the crack susceptibility significantly.

The curves of $T$ vs. $\left(f_{S}\right)^{1 / 2}$ for alloys with $1.0 \mathrm{wt} \% \mathrm{Mg}$ are shown in Fig. 6. These alloys are located in the crack susceptibility map along a horizontal line that passes through the region of high crack susceptibility in Fig. $5 \mathrm{c}$ for the case of back diffusion under a $20{ }^{\circ} \mathrm{C} / \mathrm{s}$ cooling rate. For comparison, the case of no back diffusion is also included in Fig. 6. As compared to the AlMg-Si $T-\left(f_{S}\right)^{1 / 2}$ curves shown in Fig. 3, the freezing temperature range is significantly wider and the maximum steepness $\left|d T / d\left(f_{S}\right)^{1 / 2}\right|$ is higher. This is why the Al-Cu-Mg crack susceptibility map in Fig. 5c shows significantly higher crack susceptibility (up to $6000{ }^{\circ} \mathrm{C}$ ) than the Al-Mg-Si crack susceptibility map in Fig. 2c (up to $2600{ }^{\circ} \mathrm{C}$ ).

In Fig. 7 the crack susceptibility index, i.e., the maximum steepness $\left|d T / d\left(f_{S}\right)^{1 / 2}\right|$, is plotted against the $\mathrm{Cu}$ content at a constant $\mathrm{Mg}$ content of $1.0 \mathrm{wt} \%$. In the curve without back diffusion, the peak occurs at $1.0 \mathrm{wt} \% \mathrm{Cu}$. This peak corresponds to the $1.0 \mathrm{wt} \% \mathrm{Cu}$ curve in Fig. 7a, which has the highest crack susceptibility, that is, the highest maximum steepness $\left|d T / d\left(f_{S}\right)^{1 / 2}\right|$. Likewise, in Fig. 7 the curve with back diffusion under a $20{ }^{\circ} \mathrm{C} / \mathrm{s}$ cooling rate 
shows a peak at $2 \mathrm{wt} \% \mathrm{Cu}$. This peak corresponds to the $2 \mathrm{wt} \% \mathrm{Cu}$ curve in Fig. 6b, which has the highest maximum steepness $\left|d T / d\left(f_{S}\right)^{1 / 2}\right|$, that is, the highest crack susceptibility index.

\subsection{Al-Cu-Si}

Fig. 8 shows the crack susceptibility maps of the ternary Al-Cu-Si system. Again, the crack susceptibility decreases in the order of no back diffusion, back diffusion under the cooling rate of $100^{\circ} \mathrm{C} / \mathrm{s}$ and back diffusion under the cooling rate of $20^{\circ} \mathrm{C} / \mathrm{s}$. Without back diffusion the highest crack susceptibility is $1.1 \times 10^{4}{ }^{\circ} \mathrm{C}$ and near $\mathrm{Al}-1.5 \mathrm{Cu}$ as shown in Fig. 8a. With back diffusion under the cooling rate of $100^{\circ} \mathrm{C} / \mathrm{s}$, the highest crack susceptibility, as shown in Fig. $8 \mathrm{~b}$, is $5.5 \times 10^{3}{ }^{\circ} \mathrm{C}$ and near $\mathrm{Al}-1.9 \mathrm{Cu}-0.3 \mathrm{Si}$. With back diffusion under the cooling rate of $20^{\circ} \mathrm{C} / \mathrm{s}$, the highest crack susceptibility is $4.5 \times 10^{3}{ }^{\circ} \mathrm{C}$ and near $\mathrm{Al}-1.9 \mathrm{Cu}-0.4 \mathrm{Si}$ as shown in Fig. 8c. Thus, back diffusion tends to have a greater effect on the level of the highest crack susceptibility than the location.

Fig. 8d shows the crack susceptibility map constructed from results of crack susceptibility tests of the ternary Al-Cu-Si alloy system using the restrained-weld method [21]. The black dots indicate the compositions of the alloys tested. This map shows that two separated regions of high crack susceptibility exist. However, the calculated map in Fig. 8c shows only one single region of high crack susceptibility. To improve the resolution of the calculated map, the grid spacing of $0.5 \mathrm{wt} \% \mathrm{Cu}$ was reduced to $0.25 \mathrm{wt} \% \mathrm{Cu}$ between 0 and $1 \mathrm{wt} \% \mathrm{Cu}$. Likewise, the grid spacing of $0.5 \mathrm{wt} \% \mathrm{Si}$ was reduced to $0.25 \mathrm{wt} \% \mathrm{Si}$ between 0 and $1 \mathrm{wt} \% \mathrm{Si}$. However, the calculated map was still like that shown in Fig. 8c. Thus, the discrepancy between Fig. 8c and d was not because the grid spacing of $0.5 \mathrm{wt} \%$ was too coarse to allow two separated regions of high crack susceptibility to be calculated. 
Although two separated regions of high crack susceptibility are shown in Fig. 8d, the number of alloys tested (as shown by the black dots) is too low to tell if the two separated regions of high crack susceptibility actually exist. The single larger region indicated by a lower crack length of 6 inches or $15.24 \mathrm{~cm}$ seems more reliable. If the center of this region is taken as near $\mathrm{Al}-1.5 \mathrm{Cu}-0.4 \mathrm{Si}$, it is close to the highest crack susceptibility near $\mathrm{Al}-1.9 \mathrm{Cu}-0.4 \mathrm{Si}$ of the calculated map in Fig. 8c. This indicates that the calculated map seems in good agreement with the observed one. Another Al-Cu-Si crack susceptibility map was constructed from the results of crack susceptibility tests using the ring-casting method [21]. It also showed two separated regions of high crack susceptibility. However, this was caused by the existence of two crack susceptibility peaks along the Al-Cu side of the ternary Al-Cu-Si map. These two peaks, one near $\mathrm{Al}-0.5 \mathrm{Cu}$ and the other near $\mathrm{Al}-3.5 \mathrm{Cu}$, can be seen in the crack susceptibility curve of the binary $\mathrm{Al}-\mathrm{Cu}$ alloy system constructed from the results of crack susceptibility tests using the ring casting method [23]. The same curve constructed from the results of crack susceptibility tests using the constraint-weld method, however, showed one clear peak near $\mathrm{Al}-3 \mathrm{Cu}$, consistent with the Al-Cu side of the ternary Al-Cu-Si map shown in Fig. 8d.

The curves of $T$ vs. $\left(f_{S}\right)^{1 / 2}$ for alloys with 2 wt $\% \mathrm{Cu}$ are shown in Fig. 9. These alloys are located in the crack susceptibility map along a horizontal line that passes through the region of high crack susceptibility in Fig. $8 \mathrm{c}$ for the case of back diffusion under a $20{ }^{\circ} \mathrm{C} / \mathrm{s}$ cooling rate. The case of no back diffusion is also included in Fig. 9 for comparison. As compared to the Al$\mathrm{Cu}-\mathrm{Mg} T-\left(f_{S}\right)^{1 / 2}$ curves shown in Fig. 6, the freezing temperature range is narrower and the maximum steepness $\left|d T / d\left(f_{S}\right)^{1 / 2}\right|$ is lower. This is why the Al-Cu-Si crack susceptibility map in Fig. $8 \mathrm{c}$ shows lower crack susceptibility (up to $4500{ }^{\circ} \mathrm{C}$ ) than the $\mathrm{Al}-\mathrm{Cu}-\mathrm{Mg}$ crack susceptibility map in Fig. 5c (up to $6000{ }^{\circ} \mathrm{C}$ ). Before leaving Fig. 9, it should be pointed out that arrowheads in 
the lower right corners of Fig. 9a and $\mathrm{b}$ indicate the locations of the maximum steepness $\left|d T / d\left(f_{S}\right)^{1 / 2}\right|$ in all $T-\left(f_{S}\right)^{1 / 2}$ curves with 1 to $4 \mathrm{wt} \% \mathrm{Si}$.

In Fig. 10 the crack susceptibility index, i.e., the maximum steepness $\left|d T / d\left(f_{S}\right)^{1 / 2}\right|$, is plotted against the $\mathrm{Si}$ content at a constant $\mathrm{Cu}$ content of 2 wt\%. In the curve without back diffusion, the peak occurs at $0 \mathrm{wt} \% \mathrm{Si}$. This peak corresponds to the $0 \mathrm{wt} \% \mathrm{Si}$ curve in Fig. 9a, which has the highest crack susceptibility, that is, the highest maximum steepness $\left|d T / d\left(f_{S}\right)^{1 / 2}\right|$. As shown, the crack susceptibility index remains nearly unchanged beyond $1 \mathrm{wt} \% \mathrm{Si}$. This is because, as indicated by the arrowhead in the lower right corner of Fig. 9a, the maximum steepness $\left|d T / d\left(f_{S}\right)^{1 / 2}\right|$ in all the $T-\left(f_{S}\right)^{1 / 2}$ curves with 1 to $4 \mathrm{wt} \% \mathrm{Si}$ is essentially identical. Likewise, in Fig. 10 the curve with back diffusion under a $20{ }^{\circ} \mathrm{C} / \mathrm{s}$ cooling rate shows a peak between 0 and $0.5 \mathrm{wt} \% \mathrm{Si}$. This peak corresponds to a curve between those for 0 and $0.5 \mathrm{wt} \% \mathrm{Si}$ in Fig. 9b, which has the highest maximum steepness $\left|d T / d\left(f_{S}\right)^{1 / 2}\right|$.

\subsection{Crack Susceptibility Index and Ring Casting Test}

As shown previously in Sections 3.1 and 3.2, the calculated results based on the crack susceptibility index agree well with the experimental results from ring casting tests. Although the crack susceptibility index has already been shown to agree well with results of crack susceptibility tests in both welding and casting $[5,9,14,17,24]$, its agreement with results of the ring casting tests shown in the present study can be further explained. To do this, in Fig. 11 some background information about the ring casting test is related to that of the crack susceptibility index.

Consider first the ring casting test. As shown in Fig. 11a, the mold for ring casting consists of a core, a ring and a bottom piece [21-23, 25]. The axial direction of the mold is $\mathbf{z}$, radial direction $\mathbf{r}$ and circumferential direction $\boldsymbol{\theta}$. In the case of $\mathrm{Al}$ ring casting, the mold is 
usually made of cast iron or steel. The liquid metal is poured into the open annulus between the core and the ring. As the metal cools and solidifies, solidification shrinkage (because solid density > liquid density) and thermal contraction cause it to contract. Free contraction of the solidifying metal in the radial direction, however, is obstructed by the core. Thus, severe tension can be induced in the solidifying metal in the circumferential direction $\theta$, that is, the normal stress $\sigma_{\theta \theta}$. If intergranular cracks are initiated at the core surface by $\sigma_{\theta \theta}$, they can propagate in the radial direction $\boldsymbol{r}$ along an essentially vertical plane as illustrated in Fig. 11b.

Tension can also develop in the solidifying metal in the axial direction as shown by $\sigma_{z z}$ in Fig. 11a especially if the annular space is very deep. When the metal begins to solidify and contract tightly on the inner core, it cannot contract freely in the axial direction. Thus, tension can be induced in the solidifying metal in the axial direction $\mathbf{z}$, that is, the normal stress $\sigma_{z z}$. If intergranular cracks are initiated at the core surface by $\sigma_{z z}$, they can propagate in the radial direction $\boldsymbol{r}$ along an essentially horizontal plane.

Drezet et al. [26] studied hot tearing in a ring-shaped casting of Al-4.5Cu alloy. The mold was very different from the typical ring casting mold shown in Fig. 11a. It consisted of a cylindrical container $130 \mathrm{~mm}$ in diameter and $60 \mathrm{~mm}$ high as the ring and a vertical water-cooled tube $20 \mathrm{~mm}$ in diameter as the core. The ring-shaped casting had a $20 \mathrm{~mm} \mathrm{ID,} 55 \mathrm{~mm}$ wall thickness and $60 \mathrm{~mm}$ height. Cracks induced by both $\sigma_{\theta \theta}$ and $\sigma_{z z}$ were observed near the inner surface of the casting. The normal stresses $\sigma_{\theta \theta}$ and $\sigma_{z z}$ during solidification were calculated. A critical strain rate calculated according to the RDG criterion [4] was used to determine if hot tears could occur and how far they could propagate into the ring-shaped casting, that is, the crack lengths. 
The results of ring casting tests shown in Figs. $2 \mathrm{~d}$ and $5 \mathrm{~d}$ were obtained using a mold similar to that shown in Fig. 11a, with a core of $38.1 \mathrm{~mm}$ diameter and $25.4 \mathrm{~mm}$ height, and a ring of $58.4 \mathrm{~mm}$ ID (inner diameter), $96.5 \mathrm{~mm}$ OD (outer diameter) and $19.1 \mathrm{~mm}$ height. Thus, the resultant ring castings had an ID of $38.1 \mathrm{~mm}$, a wall thickness of $10.2 \mathrm{~mm}$ and a height near $19.1 \mathrm{~mm}$. The crack susceptibility of a particular alloy was assessed by measuring the total length of cracks on all surfaces of the ring casting. The tension induced in the solidifying metal was enough to cause severe cracking in crack susceptible alloys and less but still significant cracking in less crack susceptible alloys. Photos of the top surfaces of ring castings produced from this mold showed radial (transverse) cracks through their entire thickness. For instance, in a single ring casting four such cracks were visible in $\mathrm{Al}-0.6 \mathrm{Si}$, three in $\mathrm{Al}-1.0 \mathrm{Si}$ and one in $\mathrm{Al}-$ 0.25Si [21]. (Al-0.25Si is only slightly crack susceptible.) Campbell [27] also pointed out that for crack susceptible alloys, transverse tears can occur all around the ring. Thus, the ring casting mold was designed to cause severe cracking in crack susceptible alloys and less but still significant cracking in less crack susceptible alloys. In this way, a crack susceptibility curve (for binary alloys) or map (for ternary alloys) could be established ranging from pure $\mathrm{Al}$ to more highly alloyed Al alloys [21-23, 25]. Had the mold been designed to produce castings with a significantly smaller ID and a significantly thicker wall, cracking could have been significant only in the most crack susceptible alloys and the crack susceptibility curve or map could have shown nearly zero crack lengths except for the most crack susceptible alloys.

Consider now the crack susceptibility index $\left|d T / d\left(f_{S}\right)^{1 / 2}\right|$ near $\left(f_{S}\right)^{1 / 2}=1$. The rectangular box in Fig. 11b represents a small volume in the solidifying metal at the core surface (vertical) in which two columnar dendritic grains (horizontal) are growing side by side from the core surface in the radial direction $\boldsymbol{r}$. This box is enlarged in Fig. 11c to show the longitudinal cross-sections 
of the two grains. The circumferential tension $\sigma_{\theta \theta}$ can cause grain \#2 to move laterally away from grain \#1 to cause intergranular cracking (i.e., tears like those shown in Fig. 11b). As explained previously $[5,9]$ and also in Fig. 11d, near the end of solidification, where cracking occurs, the characteristic grain radius $R$ is essentially proportional to the square root of fraction solid $f_{S}$. Thus, near the end of solidification the lateral growth rate of grains $d R / d t$ is proportional to $\left|d\left(f_{S}\right)^{1 / 2} / d t\right|$, which equals $|d T / d t| /\left|d T / d\left(f_{S}\right)^{1 / 2}\right|$, where $t$ is time. So, $d R / d t$ is inversely proportional to $\left|d T / d\left(f_{S}\right)^{1 / 2}\right|$. Therefore, a high $\left|d T / d\left(f_{S}\right)^{1 / 2}\right|$ near the end of solidification suggests the grains grow laterally toward each other slowly, unable to bridge together quickly to resist cracking. It also suggests that the grains can grow much more slowly in the lateral direction than in the forward direction (r), thus forming a long liquid channel along the grain boundary. Because of the viscosity of liquid [8], a long grain-boundary channel resists the flow of intergranular liquid that is needed to feed shrinkage and resist cracking. A long grainboundary channel can also act as a sharp notch to initiate cracking. Thus, an alloy with a high $\left|d T / d\left(f_{S}\right)^{1 / 2}\right|$ near $\left(f_{S}\right)^{1 / 2}=1$ can be expected to be susceptible to cracking during solidification (hoop tears). As mentioned previously, the validity of the crack susceptibility index has already been verified by the results of crack susceptibility tests in both welding and casting $[5,9,14,17$, 24].

Consider Fig. 11c again. In deriving the criterion for cracking during solidification, Kou considered a volume element $\Omega$ in the liquid between two growing columnar grains near the end of solidification [5]. If the rate of space increase in $\Omega$ due to the separation of the grains from each other under tension exceeds the sum of the rate of space decrease due to the lateral growth of the grains toward each other and the rate of space decrease due to liquid feeding along the grain boundary, a void (i.e., crack) can form in $\Omega$. (This criterion was expressed in terms of the 
critical local deformation rate or strain rate to cause cracking [5].) For an alloy with a high crack susceptibility index, this criterion for cracking is easy to satisfy because of the slow lateral growth rate of grains and the difficult liquid feeding associated with a high $\left|d T / d\left(f_{S}\right)^{1 / 2}\right|$ near

$\left(f_{S}\right)^{1 / 2}=1$ (Fig. 11e). Since the surface of a solidifying metal is an effective nucleating site [28], in the ring casting test of an alloy with a high crack susceptibility index, multiple cracks can initiate in the metal at the core surface. The cracks can be expected to propagate in the radial direction $\boldsymbol{r}$ through the thickness of the ring casting because the criterion for cracking is easily satisfied. Thus, an alloy with a higher crack susceptibility index can be expected to have a long total crack length in the ring casting test. This explains why the calculated results based on the crack susceptibility index can agree well with the experimental results from ring casting tests.

\subsection{Comparison with previous predictions}

Yang and Lin [29] predicted the crack susceptibility maps of ternary Al alloy systems using the solidification model of Clyne and Davies [30]. In this model the range of $0.90<f_{S}<$ 0.99 is assumed to be vulnerable to cracking due to grain separation. The range of $0.40<f_{S}<$ 0.90 is assumed to relieve stress through mass and liquid feeding. The ratio $t_{V} / t_{R}$ is taken as a crack susceptibility coefficient, where $t_{V}$ is the vulnerable time period in $0.90<f_{S}<0.99$ and $t_{R}$ is the time available for stress relief in $0.40<f_{S}<0.90$. To calculate $T$ as a function of time $t$, Clyne and Davies [30] proposed three different cooling modes: $1 . \mathrm{d} T / \mathrm{d} t=$ constant, $2 . \mathrm{d} Q / \mathrm{d} t=$ constant, and 3. $\mathrm{d} Q / \mathrm{d} t=$ constant $\times(t)^{-1 / 2}$, where $Q$ is the heat flow rate. Yang and Lin [29] found modes 2 and 3 worked reasonably well but not mode 1 . They decided to use mode 3 to calculate $T$ as a function of time $t$. To calculate $f_{S}$ as a function of $T$ for ternary alloys, thermodynamic software Pandat [10], Al database PanAluminum [11] and the Scheil solidification model of no back 
diffusion were used $[13,14]$. The crack susceptibility map was constructed by plotting the calculated crack susceptibility coefficient $t_{V} / t_{R}$ against composition.

The crack susceptibility map of the ternary Al-Mg-Si system was not calculated. So, no comparison can be made between their calculation and the calculation in the present study. For the ternary Al-Cu-Mg alloy system, their calculated crack susceptibility map showed the highest crack susceptibility near $\mathrm{Al}-0.9 \mathrm{Cu}-0.25 \mathrm{Mg}$ [29]. This location differs significantly from that calculated without back diffusion shown in Fig. 5a. It also differs from that calculated for back diffusion under a $20^{\circ} \mathrm{C} / \mathrm{s}$ cooling rate, which is near $\mathrm{Al}-2 \mathrm{Cu}-1.3 \mathrm{Mg}$ as shown in Fig. $5 \mathrm{c}$. As mentioned previously, the highest crack susceptibility observed in crack susceptibility tests is near $\mathrm{Al}-2 \mathrm{Cu}-1.5 \mathrm{Mg}$ as shown in Fig. $5 \mathrm{~d}$.

As for the ternary $\mathrm{Al}-\mathrm{Cu}-\mathrm{Si}$ alloy system, their calculated crack susceptibility map showed the highest crack susceptibility near $\mathrm{Al}-0.75 \mathrm{Cu}-0.2 \mathrm{Si}$ [29]. This location differs significantly from that calculated without back diffusion, which is near $\mathrm{Al}-1.5 \mathrm{Cu}$ as shown in Fig. 8a. It also differs significantly from that calculated for back diffusion under a $20^{\circ} \mathrm{C} / \mathrm{s}$ cooling rate, which is near $\mathrm{Al}-2 \mathrm{Cu}-0.3 \mathrm{Si}$ as shown in Fig. 8c. However, their highest crack susceptibility near $\mathrm{Al}-0.75 \mathrm{Cu}-0.2 \mathrm{Si}$ seems reasonably close to the lower region 8 in Fig. 8d, which is near Al$0.6 \mathrm{Cu}-0.8 \mathrm{Si}$.

The locations of the regions of high crack susceptibility calculated by Yang and Lin [29] for $\mathrm{Al}-\mathrm{Cu}-\mathrm{Mg}$ and $\mathrm{Al}-\mathrm{Cu}-\mathrm{Si}$ differ significant from those calculated without back diffusion in the present study even though in their study Pandat [10], PanAluminum [11] and the Scheil solidification model (no back diffusion) were also used. This discrepancy is not surprising because the crack susceptibility coefficient $t_{V} / t_{R}$ of Clyne and Davies [30], along with the cooling mode of $\mathrm{d} Q / \mathrm{d} t=$ constant $\times(t)^{-1 / 2}$, is fundamentally different from the crack susceptibility index 
used in the present study. The crack susceptibility index in the present study can also be used for casting. The cooling mode of $\mathrm{d} Q / \mathrm{d} t=$ constant $\times(t)^{-1 / 2}$, however, is not applicable to welding.

\section{Conclusions}

1. Crack susceptibility maps have been constructed for ternary Al-Mg-Si, Al-Cu-Mg and $\mathrm{Al}-\mathrm{Cu}-\mathrm{Si}$ alloy systems based on the maximum steepness $\left|d T / d\left(f_{S}\right)^{1 / 2}\right|$ of the curves of $T v s .\left(f_{S}\right)^{1 / 2}$ as the index for the susceptibility to cracking during solidification.

2. The level of crack susceptibility is highest without back diffusion and is significantly lower with back diffusion under the cooling rates of 100 and $20{ }^{\circ} \mathrm{C} / \mathrm{s}$. Back diffusion can also cause the location of the high-crack-susceptibility region in a crack susceptibility map to shift.

3. With back diffusion considered, either under 100 or $20{ }^{\circ} \mathrm{C} / \mathrm{s}$, the location of the highcrack-susceptibility region calculated agrees well with that observed in crack susceptibility tests, especially in the cases of Al-Mg-Si and Al-Cu-Mg.

\section{Acknowledgements}

This work was supported by the National Science Foundation under Grant No. DMR 1500367. The coauthor Liu was supported by the China Scholarship Council as a visiting graduate student at the University of Wisconsin-Madison. The authors would like to thank CompuTherm, LLC in Madison WI for the use of thermodynamic software Pandat and Al database PanAluminum and for the technical assistance of Drs. Shuanglin Chen and Chuan Zhang of CompuTherm.

\section{References}

[1] S. Kou, Welding Metallurgy, second ed., John Wiley and Sons, Hoboken, 2013, 257-300. 
[2] M.C. Flemings, Solidification Processing, McGraw-Hill, New York, 1974 (252-6, Appendix).

[3] J. Campbell, Castings, second ed., Butterworth Heinemann, Oxford, 2003, 216-247.

[4] M. Rappaz, J.M. Drezet, M. Gremaud, A new hot-tearing criterion, Metall. Mater. Trans. 30A (1999) 449-455.

[5] S. Kou, A criterion for cracking during solidification, Acta Mater. 88 (2015) 366-374.

[6] J. Campbell, private communications, United Kingdom, June 2014.

[7] N. Coniglio and C. E. Cross, Mechanisms for solidification cracking initiation and growth in aluminum welding, Metall. Mater. Trans. A 40A (2009) 2718-2728.

[8] S. Kou, Transport Phenomena and Materials Processing, John Wiley and Sons, Hoboken, 1996, 64-67.

[9] S. Kou, A simple index for predicting the susceptibility to solidification cracking in welding, Welding Journal, 94 (2015) 374s-388s.

[10] Pandat - Phase Diagram Calculation software package for Multicomponent Systems, Computherm LLC, Madison, WI 53719, 2001.

[11] PanAluminium - Thermodynamic database for Commercial Aluminum Alloys, Computherm LLC, Madison, WI 53719, 2001.

[12] G.H. Gulliver, Metallic Alloys (Appendix), Charles Griffin \& Co., Ltd., London, 1922.

[13] E. Scheil, Bemerkungen zur Schlichtkristallbildung, Z. Metallk., 34 (1942) 70.

[14] J. Liu and S. Kou, Effect of diffusion on susceptibility to cracking during solidification, Acta Materialia, 100 (2015) 359-368.

[15] W. Kurz and D.J. Fisher, Fundamentals of Solidification, 4th ed., Trans Tech Publications, Aedermannsdorf, Switzerland, 1998, pp. 234-235. 
[16] J. Liu and S. Kou, Crack Susceptibility of Binary Aluminum Alloys: Analytical Equations, in the Proceedings of Shape Casting: 6th International Symposium, Edited by: Murat Tiryakiog`lu, Mark Jolly, and Glenn Byczynski, TMS (The Minerals, Metals \& Materials Society), 2016, 11-18.

[17] J. Liu and S. Kou, Crack susceptibility of binary aluminum alloys during solidification, Acta Materialia, vol. 110, 2016, pp. 84-94.

[18] J. Liu and S. Kou, Evidence of back diffusion reducing solidification cracking, Acta Materialia, accepted.

[19] G. Neumann and C. Tuijn, Self-diffusion and Impurity Diffusion in Pure Metals: Handbook of Experimental Data, Vol. 14. Elsevier, 2011.

[20] Tecplot 360, Tecplot Inc., 3535 Factoria Blvd SE \# 550, Bellevue, WA 98006.

[21] P. H. Jennings, A. R. E. Singer and W. I. Pumphrey, Hot shortness of some high-purity alloys in the systems aluminum-copper-silicon and aluminum-magnesium-silicon, Journal of the Institute of Metals, 1948, 74:227.

[22] W.I. Pumphrey and D. C. Moore, Cracking during and after solidification in some aluminum-copper-magnesium alloys of high purity, Journal of the Institute of Metals, $1948,73: 425$.

[23] W.I. Pumphrey and J.V. Lyons. Cracking during the casting and welding of the more common binary aluminium alloys. Journal of the Institute of Metals, 1948, 74: 439.

[24] J. Liu and S. Kou, Crack Susceptibility of Binary Aluminum Alloys, Shape Casting: 6th International Symposium, Edited by: Murat Tiryakiog`lu, Mark Jolly, and Glenn Byczynski, TMS (The Minerals, Metals \& Materials Society), 2016, pp. 11-18. 
[25] A.R.E. Singer and P. H. Jennings. "Hot-shortness of the aluminium-silicon alloys of commercial purity." Journal of the Institute of Metals, 1946, 73: 197.

[26] J.M. Drezet and M. Rappaz. Study of hot tearing in aluminum alloys using the ring mold test. Modelling of Casting, Welding and Advanced Solidification Processes VIII. 1998:883-90.

[27] J. Campbell, Complete Casting Handbook: metal casting processes, metallurgy, techniques and design. $2^{\text {nd }}$ edition, Butterworth-Heinemann, 2015, p. 434.

[28] Campbell J, private communications, United Kingdom, June 2014.

[29] X. Yang and J. C. Lin, Prediction of hot tearing tendency for multicomponent aluminum alloys, Metallurgical Transactions B, 2006, 37B: 913-918.

[30] T.W. Clyne, G.J. Davies, Influence of composition on solidification cracking susceptibility in binary alloy systems, British Foundryman, 1981, 74 (4): 65-73.

\section{Figure Captions}

Fig. 1 Secondary dendrite arm spacing of aluminum alloys with cooling rate [14].

Fig. 2 Al-Si-Mg crack susceptibility maps: (a) without diffusion; (b) with diffusion under 100 ${ }^{\circ} \mathrm{C} / \mathrm{s}$ cooling rate; (c) with diffusion under $20{ }^{\circ} \mathrm{C} / \mathrm{s}$ cooling rate; (d) based on crack susceptibility tests [21]. High susceptibility region $\left(>2200{ }^{\circ} \mathrm{C}\right)$ in (c) is close to region 7 in $(\mathrm{d})$.

Fig. $3 T-\left(f_{S}\right)^{1 / 2}$ curves of Al-Si-Mg alloys at a constant $\mathrm{Mg}$ content of $0.5 \mathrm{wt} \%$ : (a) no back diffusion; (b) back diffusion under $20{ }^{\circ} \mathrm{C} / \mathrm{s}$ cooling rate. The short straight lines (blue) are tangents indicating the maximum steepness of the curves.

Fig. 4 Crack susceptibility index of Al-Mg-Si alloys at a constant Mg content of $0.5 \mathrm{wt} \%$. 
Fig. 5 Al-Cu-Mg crack susceptibility maps: (a) without diffusion; (b) with diffusion under 100 ${ }^{\circ} \mathrm{C} / \mathrm{s}$ cooling rate; (c) with diffusion under $20{ }^{\circ} \mathrm{C} / \mathrm{s}$ cooling rate; (d) based on crack susceptibility tests [22]. High susceptibility region $\left(>5000{ }^{\circ} \mathrm{C}\right)$ in (c) is close to region 12 in (d).

Fig. $6 T-\left(f_{S}\right)^{1 / 2}$ curves of Al-Cu-Mg alloys at a constant $\mathrm{Mg}$ content of $1.0 \mathrm{wt} \%$ : (a) no back diffusion; (b) back diffusion under $20^{\circ} \mathrm{C} / \mathrm{s}$ cooling rate.

Fig. 7 Crack susceptibility index of Al-Cu-Mg alloys at a constant Mg content of $1.0 \mathrm{wt} \%$.

Fig. 8 Al-Cu-Si crack susceptibility maps: (a) no diffusion; (b) diffusion under $100{ }^{\circ} \mathrm{C} / \mathrm{s}$ cooling rate; (c) diffusion under $20{ }^{\circ} \mathrm{C} / \mathrm{s}$ cooling rate; (d) crack susceptibility tests [21]. The number of alloys tested (shown by black dots) in (d) seems too low to tell if two separate regions of high crack susceptibility actually exist. The high susceptibility region (> $\left.3500^{\circ} \mathrm{C}\right)$ in (c) is within region 6 in (d) and close to its center.

Fig. $9 \mathrm{~T}-\left(\mathrm{f}_{\mathrm{S}}\right)^{1 / 2}$ curves of $\mathrm{Al}-\mathrm{Cu}-\mathrm{Si}$ alloys at a constant $\mathrm{Cu}$ content of $2.0 \mathrm{wt} \%$ : (a) no back diffusion; (b) back diffusion under $20{ }^{\circ} \mathrm{C} / \mathrm{s}$ cooling rate. Arrowheads in lower right corners of Fig. 9a and $\mathrm{b}$ indicate locations of maximum steepness $\left|d T / d\left(f_{S}\right)^{1 / 2}\right|$ in all $T$ $\left(f_{S}\right)^{1 / 2}$ curves with 1 to $4 \mathrm{wt} \% \mathrm{Cu}$.

Fig. 10 Crack susceptibility index of Al-Cu-Si alloys at a constant $\mathrm{Cu}$ content of $2 \mathrm{wt} \%$.

Fig. 11 Crack-susceptibility index and normal tensile stresses $\sigma_{\theta \theta}$ and $\sigma_{z z}$ in solidifying metal during ring casting test: (a) $\sigma_{\theta \theta}$ and $\sigma_{z z}$ at core surface (solidifying metal is omitted in order to be able to show them); (b) top view of mold and solidified metal (casting) showing radial tears caused by $\sigma_{\theta \theta}$; (c) longitudinal cross-section of columnar grains growing (horizontally) from core in radial direction; (d) transverse cross-sections of grains near $\left(f_{S}\right)^{1 / 2}=1 ;($ e $)$ crack susceptibility index $\left|d T / d\left(f_{S}\right)^{1 / 2}\right|$ near $\left(f_{S}\right)^{1 / 2}=1$. 


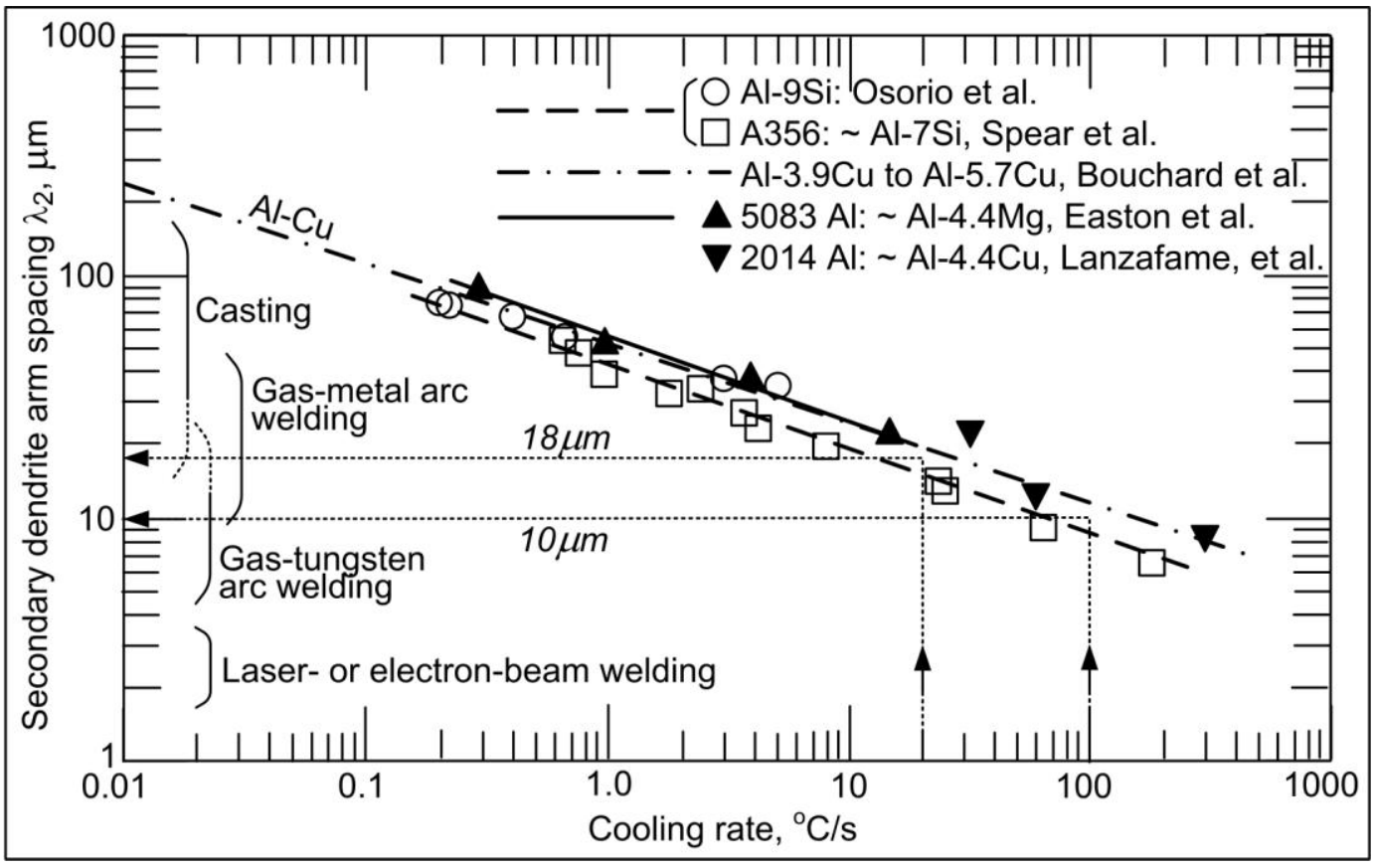




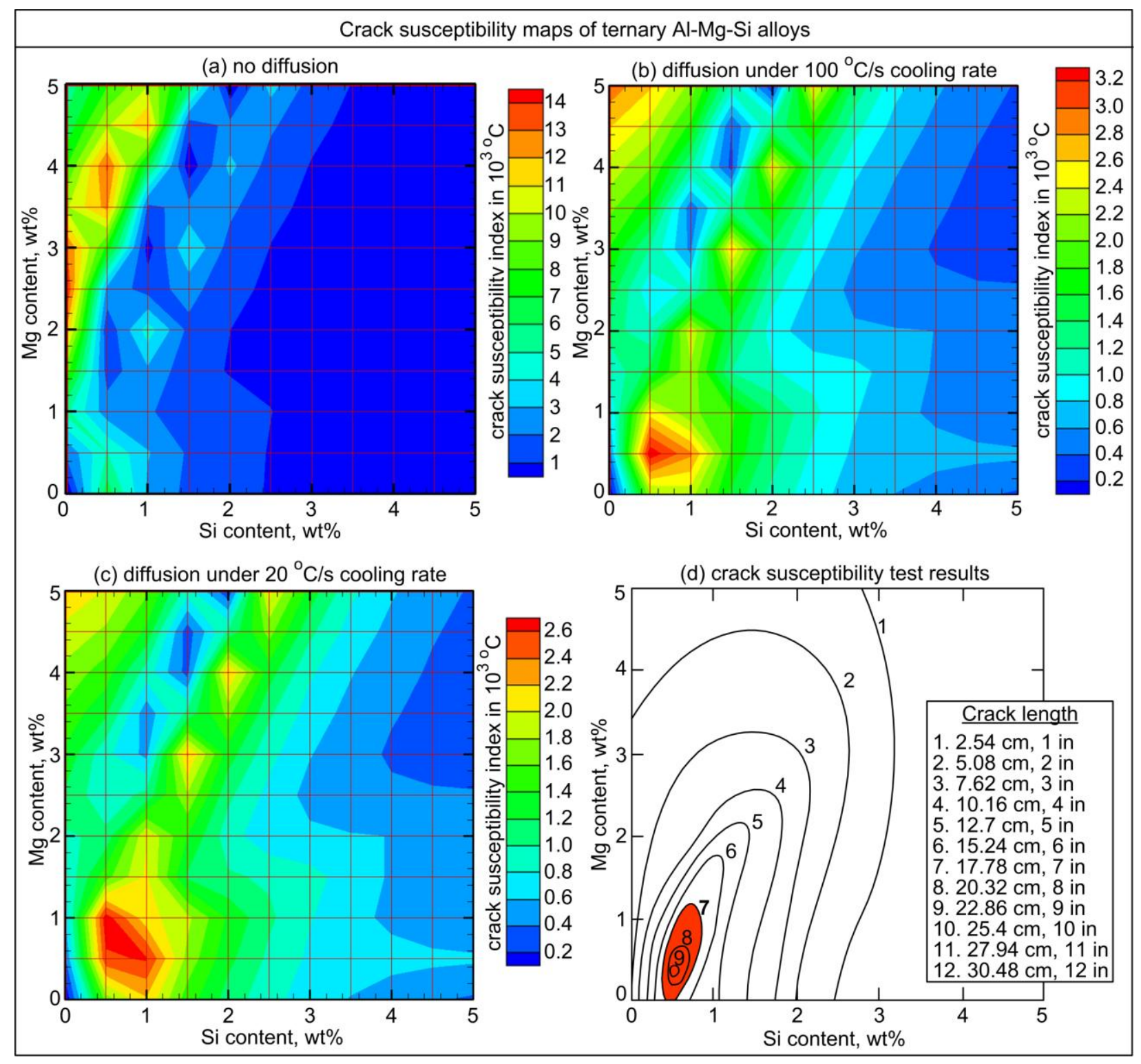




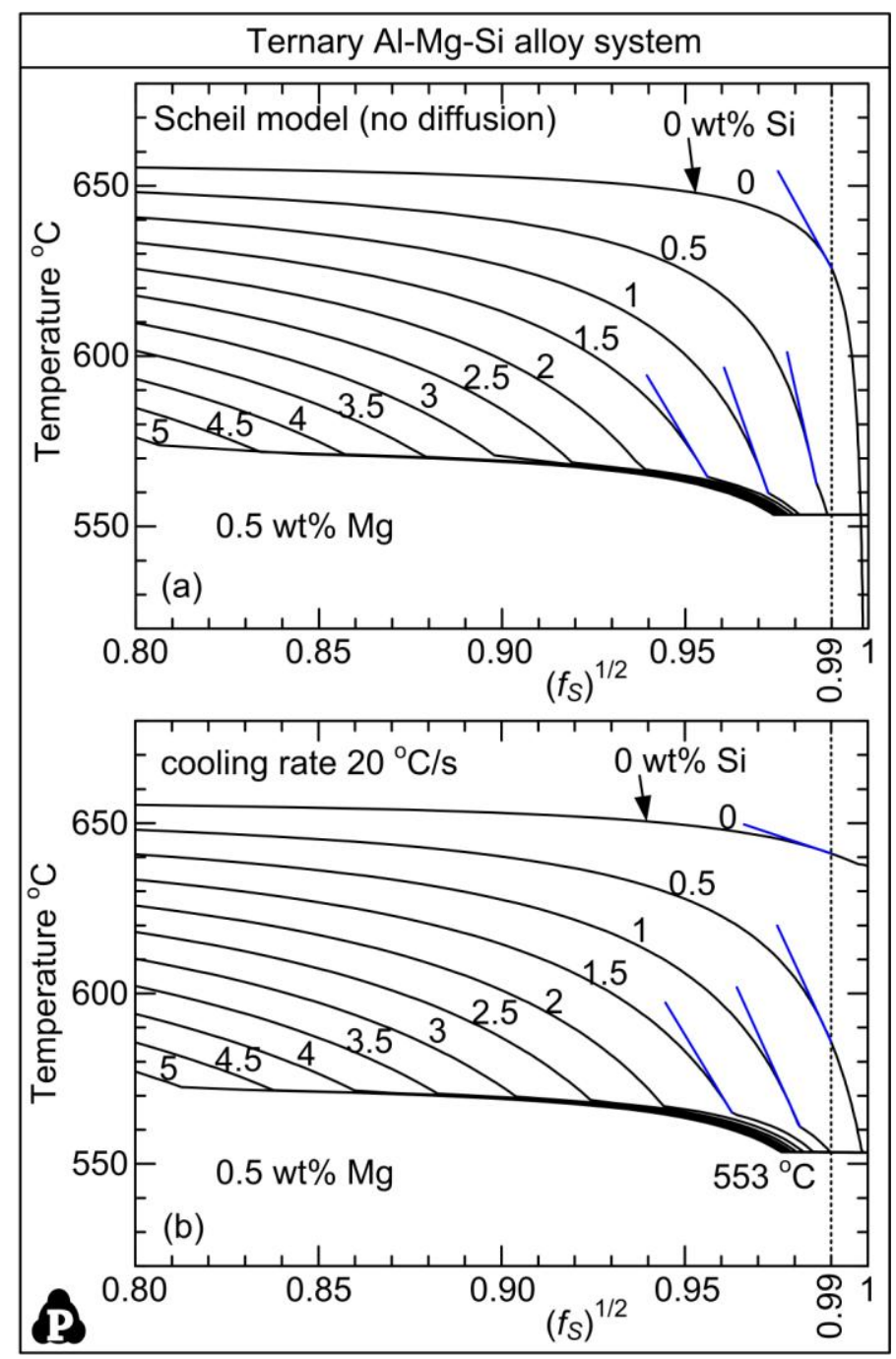




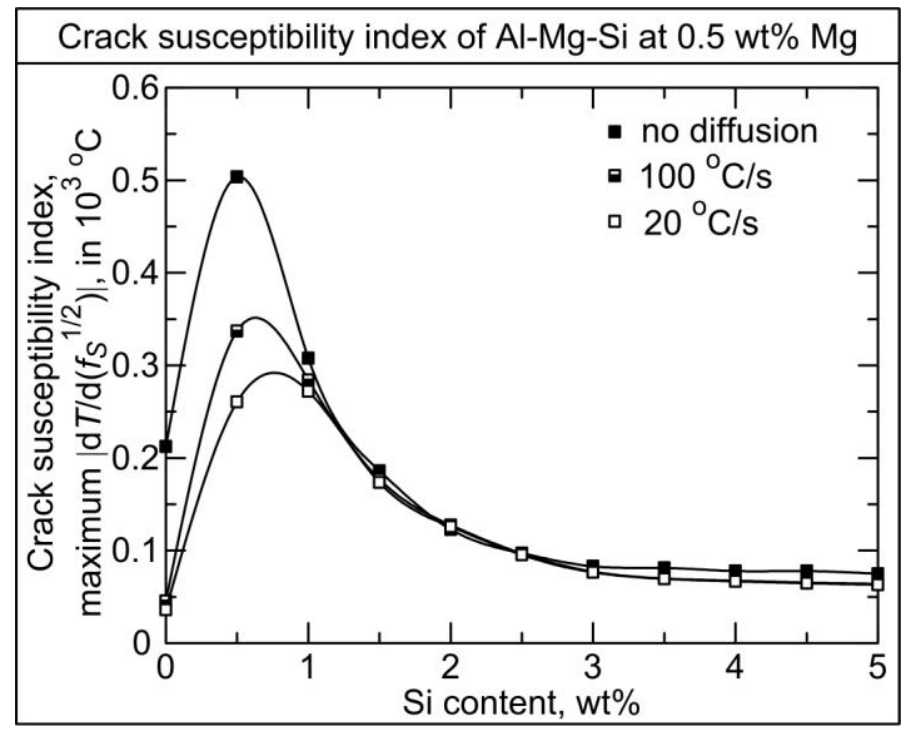




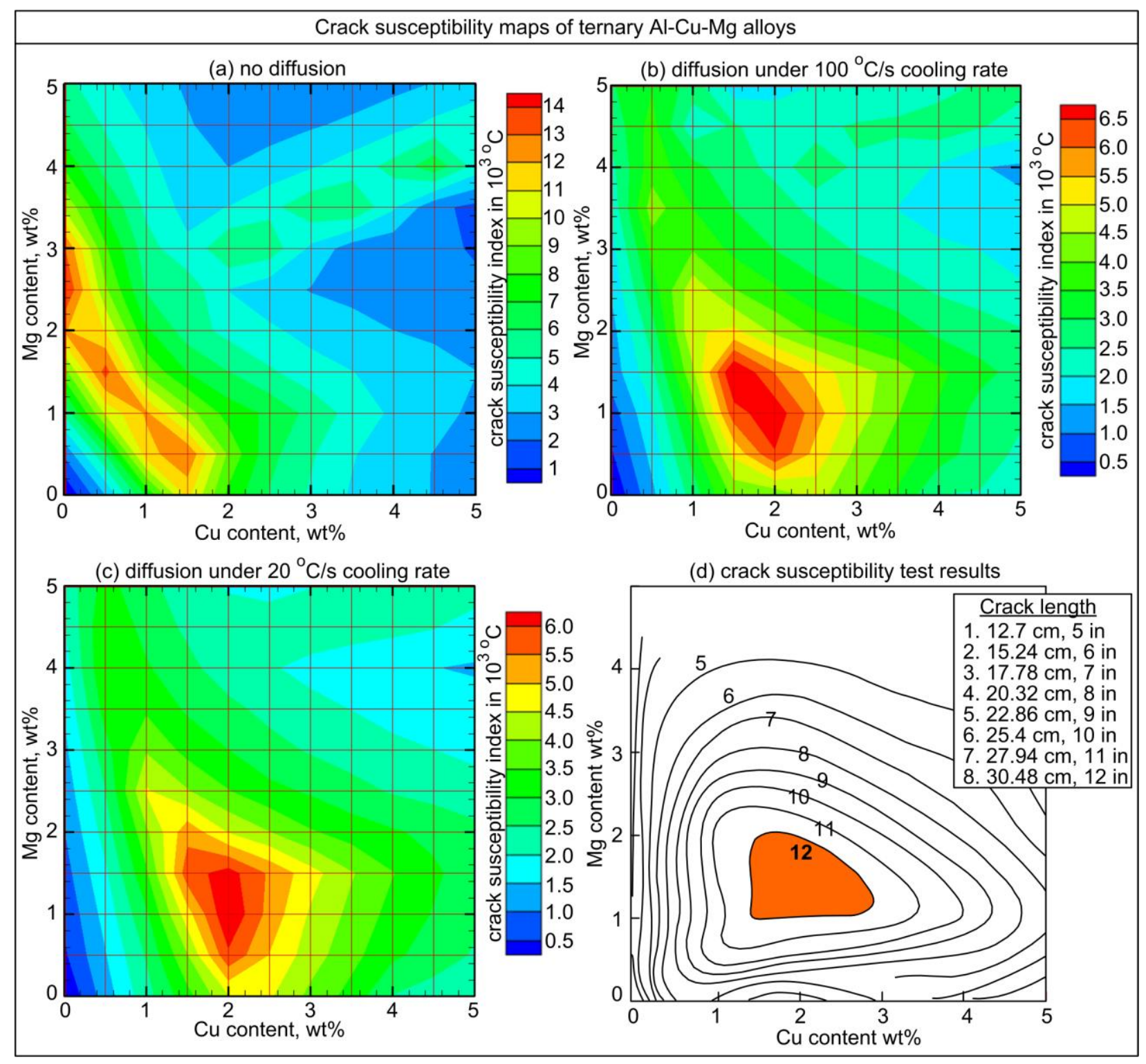




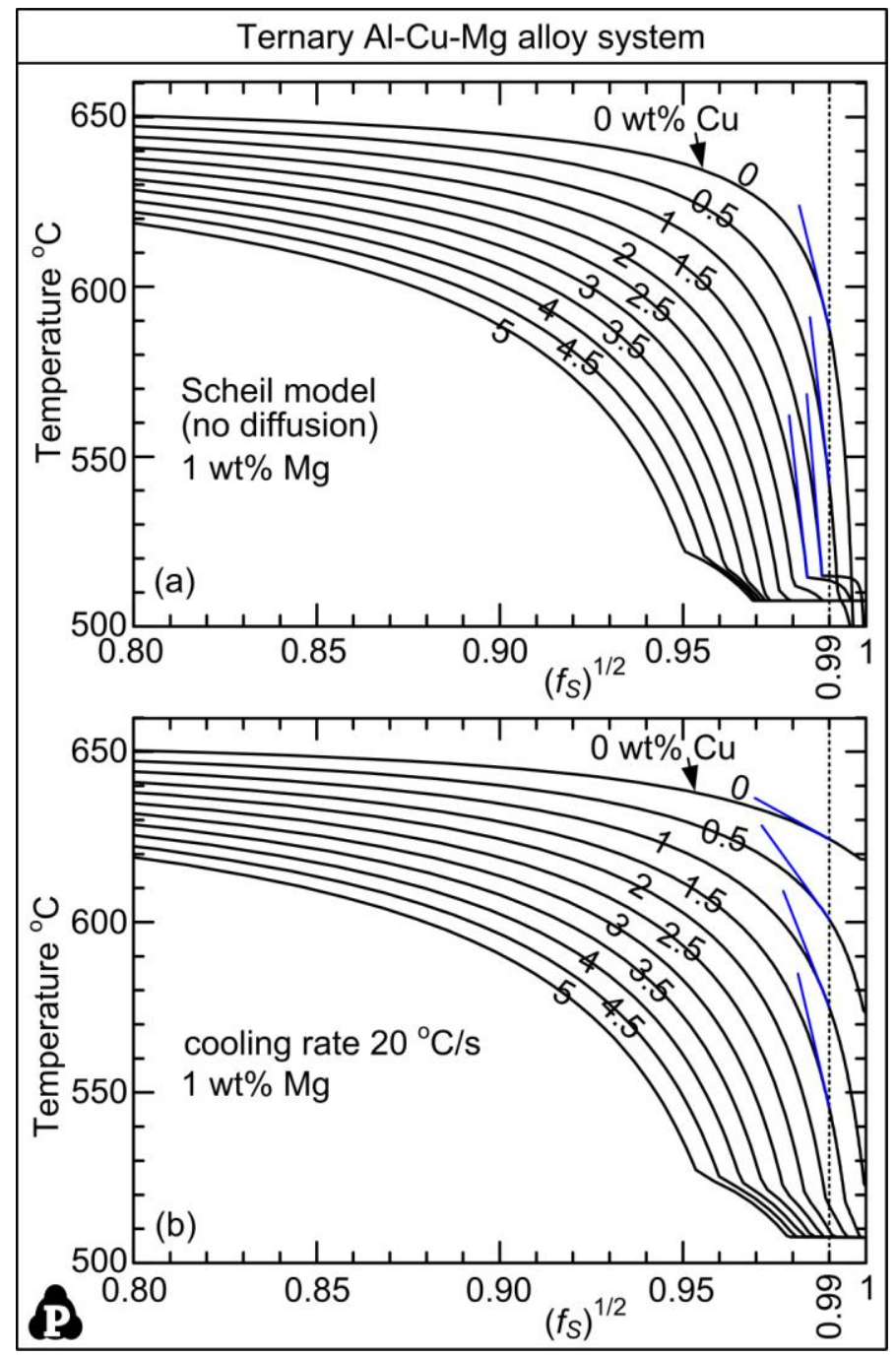




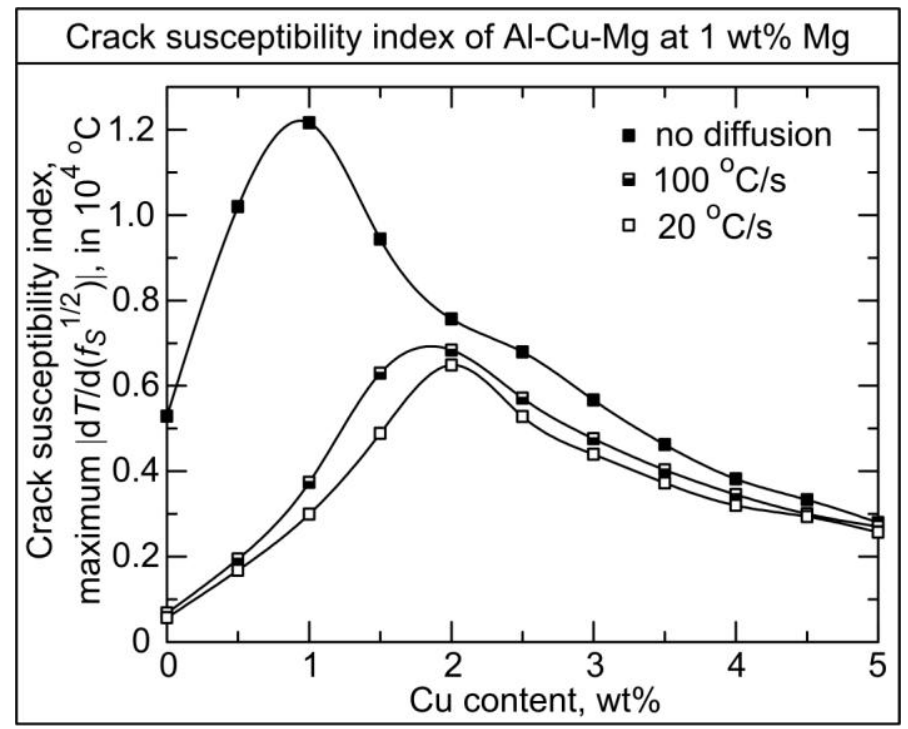




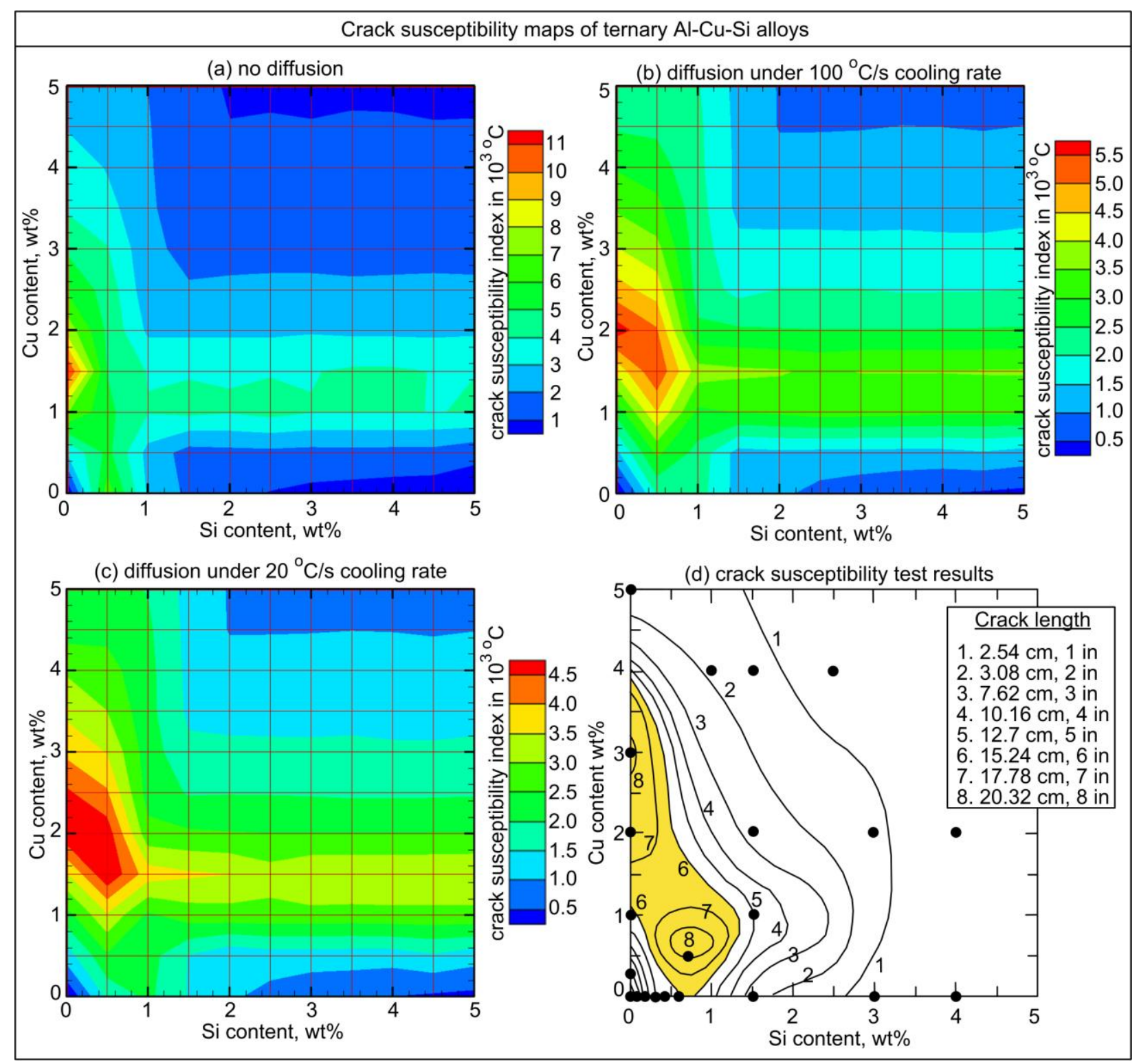




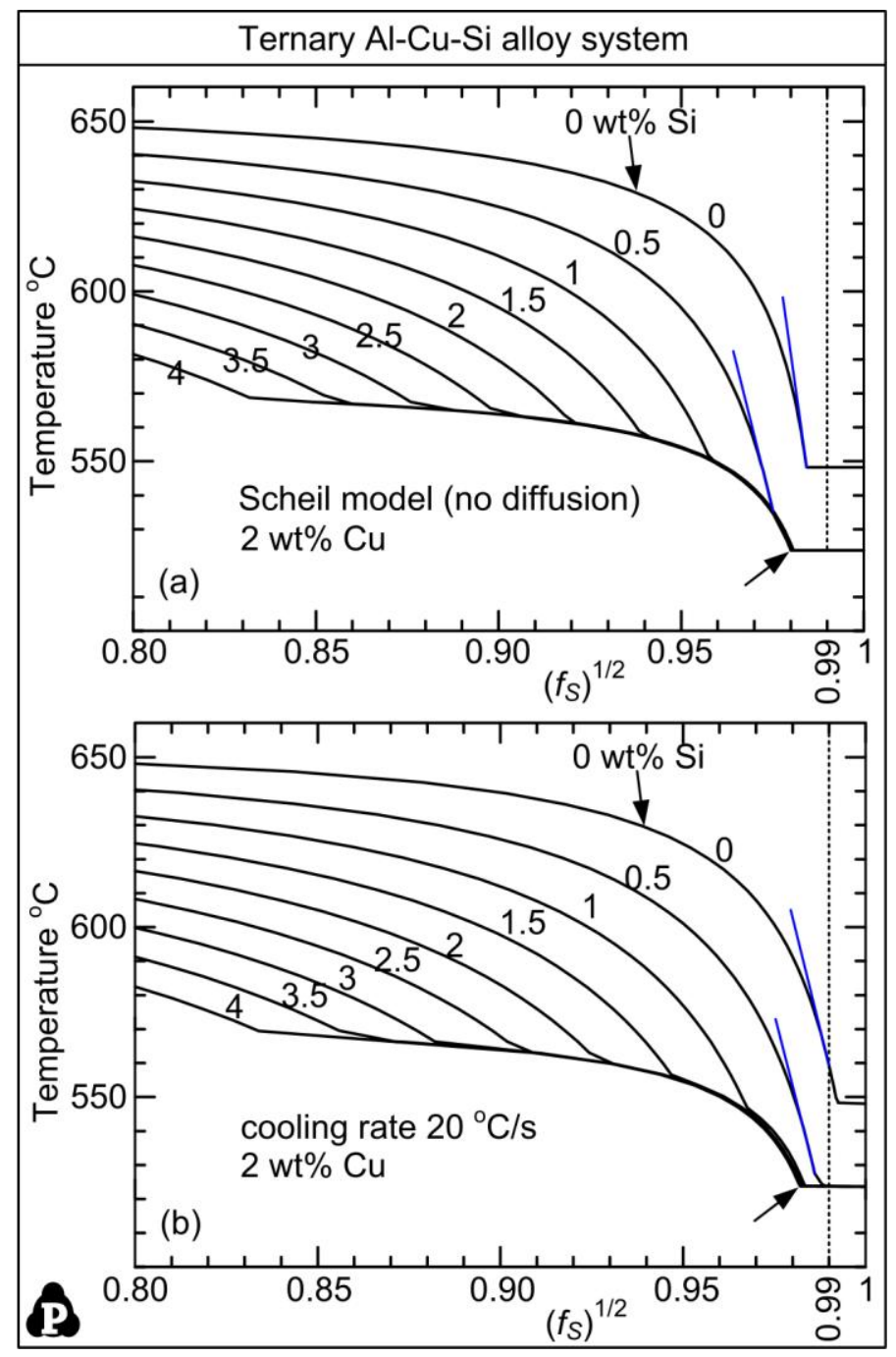




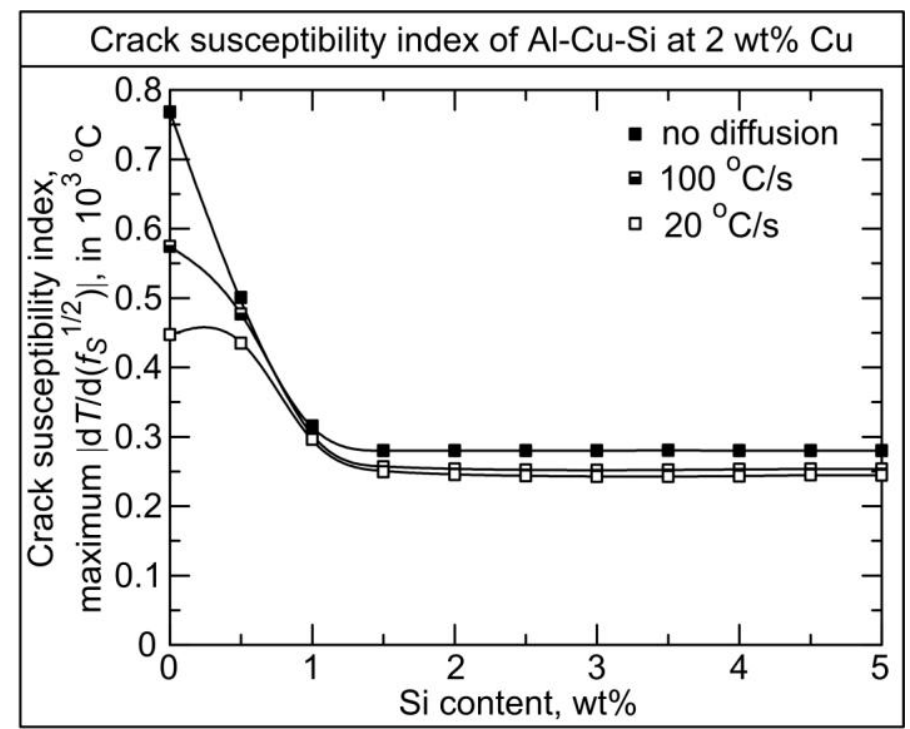




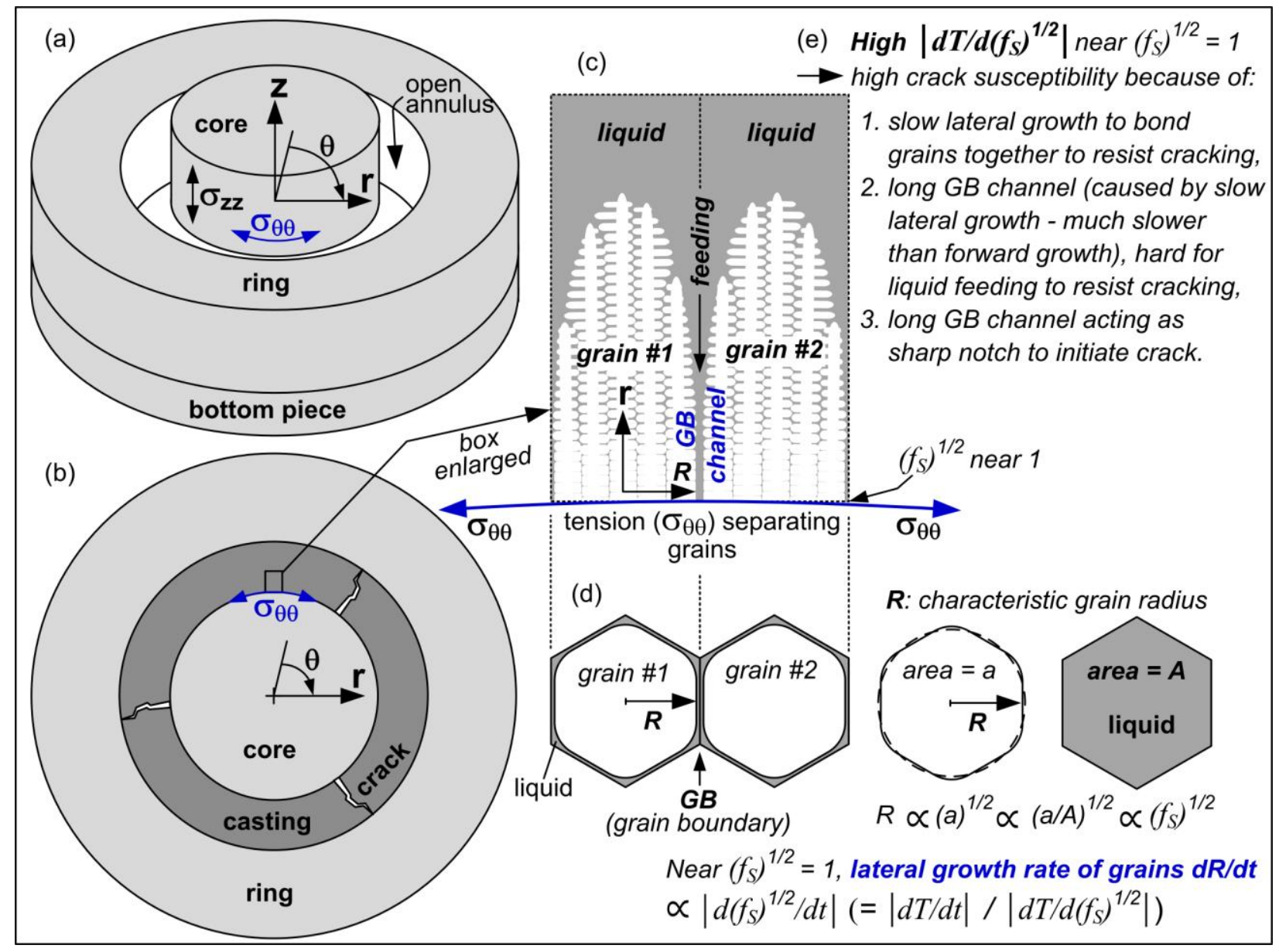


Graphic Abstract The crack susceptibility map of a ternary alloy system indicates the composition range most susceptible to cracking, which should be avoided in welding or casting. The crack susceptibility maps of ternary $\mathrm{Al}$ alloy systems $\mathrm{Al}-\mathrm{Mg}-\mathrm{Si}, \mathrm{Al}-\mathrm{Cu}-\mathrm{Mg}$ and $\mathrm{Al}-\mathrm{Cu}-\mathrm{Si}$ were calculated based on the maximum $\left|d T / d\left(f_{S}\right)^{1 / 2}\right|$ as an index for the crack susceptibility, where $T$ is temperature and $f_{S}$ fraction solid. Three levels of back diffusion were considered: no back diffusion, back diffusion under a $100{ }^{\circ} \mathrm{C} / \mathrm{s}$ cooling rate, and back diffusion under $20^{\circ} \mathrm{C} / \mathrm{s}$. The location of the region of high crack susceptibility, which is the most important part of a map, was shown. These locations were compared with those observed in crack susceptibility tests by previous investigators. With back diffusion considered, either under 20 or $100{ }^{\circ} \mathrm{C} / \mathrm{s}$, the agreement between the calculated and observed maps was good especially for Al-Mg-Si and Al$\mathrm{Cu}-\mathrm{Mg}$.

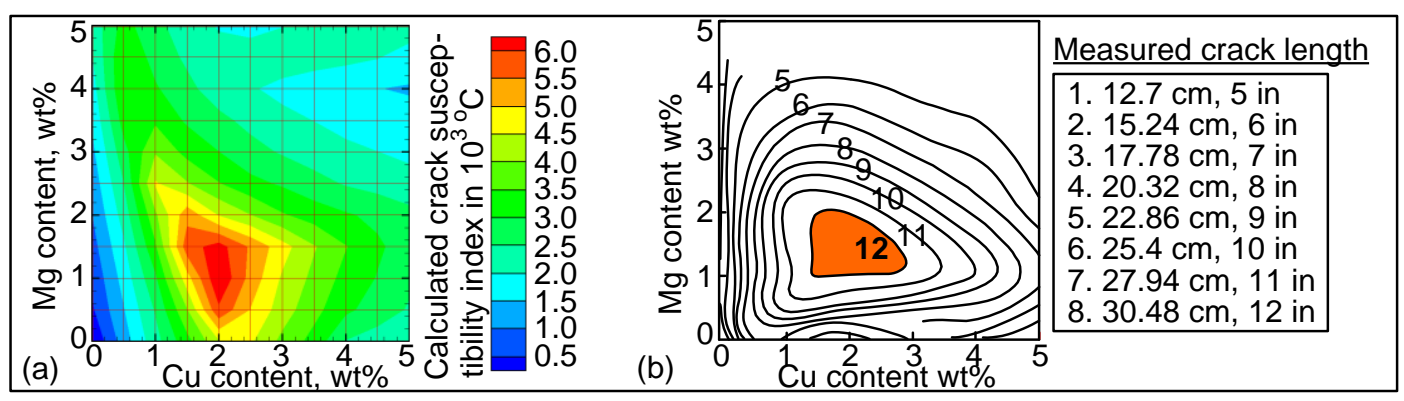

Crack susceptibility maps of $\mathrm{Al}-\mathrm{Cu}-\mathrm{Mg}$ : (a) calculated with diffusion under $20{ }^{\circ} \mathrm{C} / \mathrm{s}$ cooling rate; (b) measured. 